\title{
De la pandilla a la banda. Transformaciones de la violencia pandillera en barrios marginales en Cali ${ }^{1}$
}

\author{
From Gangs to Bands. Transformations of \\ the Gang Violence in Slums in Cali
}

\section{Da gangue para a banda criminal. Transformações da violência de gangues em bairros marginais de Cali}

1 El proyecto De la pandilla a la banda fue financiado por la oficina de apoyo a las investigaciones y publicaciones de la Universidad ICESI, en la convocatoria interna de 2014.

2 Doctor en humanidades y psicólogo. 


\title{
Resumen
}

Este artículo se propone señalar algunas características y plantear algunas hipótesis sobre la transformación reciente del conflicto urbano en Cali (Colombia), a partir del ingreso de los jóvenes de pandillas a las bandas criminales. Se basa en entrevistas a pandilleros de los barrios Marroquín en Aguablanca y Alfonso López, a líderes comunitarios y a un miembro de una banda criminal. Se trata de observar cómo este fenómeno causa transformaciones en el ethos cultural de las pandillas: transformaciones en la manera en que habitan su territorio, su uso del tiempo, las motivaciones y razones que aducen para ejercer la violencia; y también modificaciones psicológicas y sociales como el tipo de configuración emotiva -el modelamiento de sus emociones y sentimientos- (Elías, 1990), que se adapta a una progresiva racionalización de la violencia. La tesis central es que la violencia pandillera muta en dirección a una progresiva instrumentación, a una racionalidad utilitaria que también moldea su psicología.

Palabras clave: pandillas; bandas criminales; violencia urbana; cultura de la violencia.

\begin{abstract}
This article points out some features and raises some hypothesis on the recent transformation of the urban conflict in Cali (Colombia). It follows the transformation process from the entry of young people from gangs to criminal bands. It is based on interviews with gang members from neighborhoods Marroquín in Aguablanca and Alfonso López, community leaders and a member of a criminal band. It is about observing how this phenomenon causes changes in the cultural ethos of gangs: transformations in the way in which inhabit their territory, their use of time, motivations and reasons given for violence; and, changes the type of emotional configuration -modeling of emotions and feelingssocial and psychological (Elias, 1990); which adapts to a progressive rationalization of violence. The central thesis is that gang violence mutates in the direction of progressive instrumentation, a utilitarian rationality also molding their psychology.
\end{abstract}

Keywords: gangs; organized crime; urban violence; culture of violence.

\section{Resumo}

Este artigo propõe-se assinalar algumas características e salientar algumas hipóteses sobre a transformação recente do conflito urbano em Cali (Colômbia), a partir da inserção de jovens de gangues às bandas criminais. Os dados se derivam de entrevistas a jovens de gangues de bairros do oriente de Cali, de lideranças comunitárias e de um integrante de uma banda criminal. Trata-se de observar como este fenômeno causa mudanças no ethos cultural das gangues, particularmente, no modo como habitam seu território, o uso do tempo, as motivações e razões que afirmam para exercer a violência, assim como as modificações psicológicas e sociais, entre as quais está o tipo de configuração emotiva - a modelagem das emoções e sentimentos- (Elias, 1990), que se adapta a uma progressiva racionalização da violência. A tese central é que a violência das gangues vai em direção a uma crescente instrumentalização e racionalidade utilitária que também configura sua psicologia.

Palavras-chave: gangues; bandas criminais; violência urbana; cultura da violência.

Este trabajo está bajo la licencia Creative Commons Attribution 3.0

¿Cómo citar este artículo? / How to quote this article?

Ordóñez-Valverde, J. (2017). De la pandilla a la banda. Transformaciones de la violencia pandillera en

barrios marginales en Cali. Sociedad y economía, (32), 107-126. 


\section{Introducción}

Cali (Colombia) es una ciudad especialmente violenta en un país históricamente violento 3 . En el año 2013 la tasa de homicidios en la ciudad era de 82 por cada cien mil habitantes, 66 en 2014 y 56 en 2015; aunque ha disminuido significativamente sigue siendo la más alta del país en los grandes centros urbanos. La delincuencia organizada en torno al tráfico de cocaína es en buena parte responsable de esa violencia, pero hay que reconocer que existen otras violencias que no parecen tener una base objetiva tan clara como el narcotráfico donde la pugna entre los actores en conflicto sigue un ordenamiento estratégico de monopolios de distribución y reglas del negocio. Hay otras violencias contra la mujer, la familia, las riñas callejeras, las guerras de pandillas, que se rigen por otras racionalidades más bien poco estudiadas, y sobre las cuales las ideas de una cultura de la violencia pueden dar alguna luz.

La historia de las organizaciones criminales en Cali dedicadas al narcotráfico puede, si se quiere, describirse en tres etapas: la primera de ellas entre 1985 y 1996 cuando se consolida el cartel y Cali se convierte en la capital mundial del narcotráfico; la segunda entre 1996 y 2002 que incluye la desarticulación del Cartel de Cali y el ascenso del Cartel del Norte del Valle; y la tercera que va de 2002 a nuestros días en la cual se presentan disputas entre asociaciones de narcotraficantes y la entrada de las bandas criminales nacionales al territorio vallecaucano.

En cada uno de estos períodos la organización criminal en torno al tráfico de drogas establece un conjunto de alianzas y conflictos entre los carteles y otros grupos delincuenciales como las llamadas oficinas de cobro4, las organizaciones de limpieza social5, las bandas delincuenciales, las pandillas, las guerrillas y las redes de expendio de droga al detal. Esto varía en cada uno de los momentos enunciados creando distintas figuraciones sociales y campos de conflictividad. En esta investigación interesa la última fase del último período y en particular la relación entre la delincuencia organizada y las pandillas de sectores empobrecidos en los barrios Marroquín y Alfonso López.

En este último período el campo de la violencia urbana en Cali ha venido transformándose de manera muy acelerada (aunque es difícil señalar una fecha, varios informantes coinciden en que podría ser a partir del 2012). Este cambio se ha dado por la progresiva penetración de las bandas criminales en los negocios del microtráfico urbano, la extorsión a los tenderos y los pequeños y medianos comerciantes en los barrios, además de la extensión de los servicios propios de las llamadas oficinas de cobro, (seguridad, cobro de cartera, ajuste de cuentas, sicariato, etc.). La criminalidad organizada está reclutando algunos jóvenes pertenecientes a las pandillas de los barrios marginales. Jóvenes que han ganado fama por el ejercicio de la violencia, jóvenes que destacan por su liderazgo o su

3 El $75 \%$ de las 60 ciudades colombianas tuvo entre 1991 y 2010 una tasa de homicidios por encima de 30 por cada cien mil habitantes. En 2016 la tasa nacional fue 25,9.

4 Organizaciones que ofrecen un portafolio de servicios a otras organizaciones criminales e incluso a particulares; que va desde la intimidación y las amenazas hasta el asesinato.

5 Asociaciones entre comerciantes, agentes del orden, fuerzas parapoliciales que se dedican a asesinar a drogadictos, ladrones, indigentes, homosexuales, entre otros. 
crueldad en la difícil vida de las esquinas y las calles. Este reclutamiento transforma la vida de estos jóvenes y modifica la estructura del campo de conflicto urbano. La violencia deja de ser cosa de identidad y de honor, y se "profesionaliza" para ser usada en el mundo de los negocios ilegales.

El propósito de este artículo es examinar algunas características de esas transformaciones, con la hipótesis de que la violencia pandillera se mueve entre un polo ritual y emocional -de fuerte carga afectiva- y otro polo instrumental y racional despojado de su emocionalidad y de su simbolismo original. El modelo teórico está inspirado en las tesis sobre el proceso civilizatorio de Norbert Elías (Elías, 1990) y algunos de sus continuadores (Spieremburg, 1998), en las cuales los fenómenos sociales y la subjetividad son procesos que se determinan mutuamente, y en el entendido de que la estructura de las relaciones sociales determina (parcialmente) el modelamiento de las estructuras psíquicas.

Esta investigación está basada en una metodología etnográfica, usa algunas fuentes secundarias y se apoya fundamentalmente en testimonios de testigos y protagonistas de la violencia urbana. Tiene como antecedentes las investigaciones sobre la cultura pandillera en sectores marginales de Cali, realizadas por el autor. Se basa en un conjunto de entrevistas obtenidas entre junio de 2014 y agosto de 2015 con miembros de la pandilla del Palo en el barrio Marroquín II, en el distrito de Aguablanca; y en el barrio Alfonso López con la pandilla Patioquinto del sector del jarillón del río Cauca. También se realizaron entrevistas con varios líderes comunitarios de ambos sectores que han sido testigos del acontecer del barrio.

Con la pandilla en Aguablanca hay una relación previa que se remonta a la colaboración con un proceso de rehabilitación con base en la justicia restaurativa. Este grupo de diez o doce muchachos ha cambiado en el tiempo, y son testigos privilegiados del acontecer del barrio; con cuatro de ellos se realizaron sendas entrevistas. Del barrio Marroquín II, -donde tiene asiento la pandilla- también dieron testimonio tres líderes comunitarios (informante 3) que han observado la transformación de las pandillas y la evolución del negocio del microtráfico. En Alfonso López el testimonio viene de dos viejos informantes con los cuales había un trabajo previo y que relatan lo que han visto de la penetración de las bandas criminales (informante 2).

A esto hay que añadir apartes de varias entrevistas realizadas a un miembro de una banda criminal que paga prisión en la cárcel de Buga (informante l), y que habla de cómo funciona la delincuencia organizada; además de documentos periodísticos para contextualizar la historia del narcotráfico en el Valle del Cauca. Con la comunidad del barrio y con los pandilleros entrevistados ha habido un proceso previo de trabajo etnográfico de varios años; ya se ha establecido una buena relación (rapport) y se han hecho ejercicios previos de interpretación de significados de la violencia. Ha sido como la continuación de un diálogo iniciado mucho antes. Para este artículo se privilegia la información obtenida directamente de las entrevistas, pero no debe desconocerse la construcción dialógica de conocimiento que le precede y en la cual se basa la interpretación de los significados sociales. Estos testimonios se completan con información de revistas que contextualizan un poco la historia del narcotráfico en el Valle del Cauca. 
Las pandillas en los barrios empobrecidos al margen de la ciudad de Cali solían ser pequeños grupos de jóvenes unidos por fuertes lazos emocionales; una suerte de comunidad afectiva controladora y violenta (Cerbino, 2006). Ellos "parchaban" ${ }^{6}$ juntos en las esquinas, jugaban fútbol en la calle, se drogaban en los rincones de sus dominios y defendían su territorio con un cuchillo. Eran jóvenes marginales, por fuera de la escuela y del trabajo, repudiados por la comunidad, que se dedicaban de manera poco sistemática a la delincuencia común (Perea, 2007; Rubio, 2007; Valenzuela, Nateras \& Reguillo, 2007; Vigil, 1988). Un estudio revela que su realidad cotidiana -violenta y marginal- era y sigue siendo un terreno fértil para el desarrollo de ciertos valores y creencias asociados a la masculinidad, a los códigos de honor y a una religiosidad mágica, que enaltecen y valoran positivamente la acción violenta (Ordóñez, 2015). En otras palabras: hay una cultura que subyace y que da un sustento narrativo e ideológico a la violencia de las pandillas, y está representada por los sistemas culturales del género, del honor y de la religiosidad.

Puede decirse que la violencia entre pandillas cumplía en muchos aspectos una función ritual y que esta violencia tiene un alto contenido de emocionalidad, aspectos que se resumen en la idea de que la pandilla es una comunidad honorífica. En los conflictos con las pandillas rivales, la enemistad prescinde con frecuencia de razones objetivas y se basa en odios tradicionales que se heredan por el simple hecho de pertenecer a bandos contrarios. También ocurre que las pruebas de masculinidad entre pares implican la demostración de valentía y solidaridad con el grupo, y audacia y crueldad contra el enemigo, de manera que los valores de la masculinidad se afirman mediante la violencia, más allá de las causas objetivas y estructurales de los conflictos. Lo que resulta determinante es la manera como los pandilleros interpretan los conflictos, y por eso cualquier problema es visto como una ofensa a la dignidad y al orgullo, y hasta a las cosas más triviales se las reviste de una severa trascendencia e importancia. Resolver los conflictos con violencia sanciona una forma de superioridad y encumbramiento social a los ojos de los demás. Aquel capaz de un mayor nivel de violencia, de los actos más irreflexivos y más temerarios, de una mayor brutalidad, se gana el "respeto", el temor y la admiración de sus pares.

En los episodios de venganza de las pandillas no importa mucho el tipo de problema, a veces ni siquiera la identidad o responsabilidad de la víctima; lo importante es matar un miembro cualquiera de la pandilla rival como ocurre en los crímenes de sangre en las sociedades tradicionales. Esto significa que el entramado social ha hecho de la violencia una relación social7 (Bettelheim, 1998), que hay una organización del grupo donde la rivalidad es fuente de identidad y cohesión; significa que la violencia no es la consecuencia indeseada de un conflicto puntual, sino que es una estrategia de socialización y un valor. Que la

6 Hace referencia -en el lenguaje coloquial- al hecho de reunirse en un sitio.

7 Aunque esta idea se puede deducir de varios autores, Bettelheim (1998) es especialmente claro en su texto "La violencia, un modo de relación social olvidado". Contradice la afirmación de que la violencia es el fracaso de la relación social y reconoce su valor cohesionador y forjador de la identidad de grupo. 
violencia está institucionalizada como un deber y que configura lo que se conoce como un código de honor.

Este artículo comienza con una breve contextualización de las últimas transformaciones del campo del conflicto urbano en Cali, y luego procede a describir el cambio de la vida en la pandilla a la vida en la banda, usando una serie de categorías que son: el territorio, el tiempo, el significado de la violencia y la subjetividad.

\section{El conflicto}

Para teorizar el fenómeno de las pandillas, por una parte hay que considerar los factores estructurales objetivos: la pobreza, la marginación y segregación social, la poca presencia de las instituciones del Estado y la precaria regulación legal de los conflictos en estas comunidades; hay que examinar la estructura de las relaciones sociales (Galtung, 2003), con sus instituciones, sus campos de conflicto y sus diferenciales de poder, y la manera en que se han configurado históricamente en estos barrios. Pero por otra parte, están los pandilleros -los sujetos sociales- que son una subjetividad activa en la representación de su mundo social y en la producción de su identidad. Ellos tienen capacidad de agencia en su conducta social. Esa subjetividad activa, esta psicología del pandillero que construye y se representa su realidad social, requiere de la mediación de sistemas culturales, de narrativas, ideologías y valores en torno a la masculinidad, las ideas mágico-religiosas y el honor que les permiten adaptarse funcionalmente a su duro entorno de violencia. Estos sistemas culturales expresan la contradicción social y al mismo tiempo intentan resolverla.

Desde lejos de los barrios, por fuera del contexto cotidiano de las pandillas puede parecernos que estos jóvenes se comportan sin Dios ni ley, y que su violencia parece excesiva, inútil e inmotivada. No hay muchas ganancias objetivas o materiales en las guerras de pandillas salvo el dominio de unas pocas calles; ellos no ganan dinero por matarse, antes bien se convierten en las futuras víctimas de las cadenas de venganza. ¿Qué justificaría esa violencia insensata? Al acercarse a estos jóvenes y dialogar con ellos, no es difícil empezar a entender que las guerras entre pandillas están gobernadas por reglas y prescripciones precisas, por prohibiciones y obligaciones, y por las leyes de hierro del honor (Ramírez, 2007). Los relatos sobre las guerras de pandillas siempre mencionan el heroísmo y la audacia que muestran los combatientes en el campo de batalla, allí los pandilleros ganan fama por su coraje o por su crueldad, y compiten para demostrar cómo controlan el miedo, cómo desfogan su rabia y cómo niegan la compasión al enemigo. Los combates también son una suerte de rito donde se reafirma la solidaridad del grupo, se protegen unos a otros y se multiplican los actos de nobleza, sacrificio y dignidad.

Al comienzo de este artículo se habla de la cultura pandillera en los términos en que hemos venido haciéndolo, como si fuera cosa del pasado, como si su situación ya no fuera la misma, como si algo hubiera cambiado sustancialmente. La verdad es que está produciéndose un rápido cambio del contexto y la realidad social de la violencia urbana, y no es un cambio para mejorar: las pandillas están empezando a transformarse en otra cosa, por causa de su participación en 
el tráfico de drogas, y las actividades relacionadas con este delito. La tradicional violencia de las guerras de pandillas en los barrios está haciendo el tránsito hacia una violencia mediada por la delincuencia organizada. En el informe Cali cómo vamos se señala que

\begin{abstract}
en los últimos 19 años, la incidencia del narcotráfico con su cambio de estructura en su accionar, que mudó de carteles a grupos y de grupos a bandas, las cuales se reenfocaron hacia el mercado interno urbano, el micro-tráfico con presencia territorial a través de pandillas y diversificación de actividades delictivas en alianzas con otros grupos delincuenciales. Estas mutaciones han ocasionado reacomodos internos y rivalidades que explican los cambios de tendencia en la dinámica de los homicidios (Alcaldía de Santiago de Cali, 2015, pp. 3-7).
\end{abstract}

O como sugiere otro autor refiriéndose al caso mexicano: "La violencia del crimen organizado alteró la dinámica de vida de la población en general, pero particularmente transformó las agrupaciones juveniles de barrio y su relación con el territorio y la identidad" (Cruz Sierra, 2014, p. 1). En otras palabras, las pandillas están siendo cooptadas por la delincuencia organizada, y esa delincuencia organizada está trasmutando el campo de conflicto de la violencia urbana. ¿Cómo ocurre este fenómeno? ¿Qué consecuencias tiene en la transformación del ethos cultural de vida pandillera? ¿Cómo transforma la psicología del pandillero? Estas son algunas de las preguntas que surgen ante esta nueva realidad.

La transformación de una pandilla en una banda de la delincuencia organizada siempre ha sido una posibilidad -y se pueden examinar casos puntuales del pasado en los cuales un grupo de jóvenes pandilleros toma la decisión de participar colectivamente en actividades delincuenciales como el robo a bancos o apartamentos-; pero en la situación actual hablamos de un fenómeno un tanto distinto. Es más adecuado decir que algunos miembros de las pandillas son contratados para funciones específicas dentro del negocio del tráfico de estupefacientes. Ellos son escogidos en razón de su peligrosidad social, por la fama que han obtenido en las guerras del pavimento; $y$ otros por sus habilidades específicas para llevar y traer cosas y mantener un territorio seguro. Como dicen quienes les contratan: "lo importante es que sea serio para trabajar, es decir que no se tuerza (que no traicione), que no sea sapo (que no delate), que cumpla lo que promete, que no la vaya a cagar en una vuelta (que cuando tiene una misión no cometa errores o sea irresponsable)" (Informante 1, comunicación personal, 12 de agosto 2014).

Los pandilleros que resultan contratados por una banda pueden a su vez subcontratar los servicios de algunos compañeros de la pandilla (lo que hoy en día se llama tercerizar), y esto cambia el tipo de relación que sostienen con el grupo, porque ya no es la amistad lo que prima sino una relación de trabajo: "Ya estamos es camellando (trabajando), entonces hay que ponerse serios..." (Informante 2, comunicación personal, enero 2015). En resumen podemos decir que el paso de la pandilla a la banda supone una transformación del ethos cultural de la pandilla de una comunidad emocional, con su conjunto de creencias mágico-religiosas y sus códigos de honor, a una estructura más jerarquizada y organizada en torno a una actividad económica ilícita y con otro código de honor. Vamos a proponer algunas categorías analíticas donde puede observarse 
lo que se transforma en este tránsito. Estas son: el campo de conflicto, que se transforma con el ingreso de nuevos actores y nuevas reglas, y la redefinición de los intereses y los recursos en juego; el uso del espacio, que pasa de ser un referente vital identitario a un corredor estratégico para las actividades de un negocio ilícito; el uso del tiempo, que pasa del ocio de la esquina, por fuera de la escuela y el trabajo, al tiempo regulado y controlado del "trabajo" violento; las motivaciones de la violencia, que de ciertas prácticas ritualizadas va mutando a una violencia racionalizada; y por último la transformación de la subjetividad del pandillero cuya configuración emotiva es apasionada e intensa y se transforma en una estructura más racional y controlada. Aunque desborda el propósito de este trabajo, no es desacertado vincular estos cambios identitarios con categorías como género y masculinidad: "An analysis from the perspective of masculinity studies will overcome the visions that criminalize young men, and will confirm the close relation between the cultural construction of masculinity and the exercise of violence expressed in juvenile delinquency" (Hernández, 2015, p. 56). Algunas hipótesis de este trabajo ayudarían a comprender algunos aspectos de la masculinidad violenta.

En lo que sigue se van a desarrollar estas categorías con más detalle.

\section{La estructura del campo de conflicto}

Para el caso de Cali, el narcotráfico tiene un importante impacto en la definición del campo de conflictividad violento. Buena parte de la violencia homicida corresponde a delitos vinculados de una u otra manera con el comercio ilegal de drogas. Por supuesto que este negocio no es la única causa de las muertes en la ciudad, pero, aparte de su incidencia directa, también contribuye al afianzamiento de valores culturales que apoyan la resolución violenta de los conflictos. Como decía el informe Cali cómo vamos citado más arriba, ese delito ha sufrido importantes transformaciones en las últimas dos décadas, desde las inmensas empresas monopólicas de la exportación que eran los carteles en los años de 1990 cuando Cali era la capital mundial del narcotráfico, hasta su desagregación en pequeños carteles que controlan una ruta y guardan un perfil más bajo. A esto se suma el progresivo involucramiento de la guerrilla insurgente de las FARC en varias fases de la cadena productiva del negocio de la droga y del tránsito de esta mercancía hacia la zona del Océano Pacífico y el puerto de Buenaventura; y más recientemente, la decidida participación de las bandas criminales en el tráfico interno y la exportación de la droga, con la consecuente lucha contra otras organizaciones por el control de zonas estratégicas y de mercados para el negocio. De esto último quizá lo más significativo es la penetración en el mercado interno y la ampliación del control territorial urbano de parte de la delincuencia organizada, que se ha aplicado a la generación de estrategias de transporte y venta de la droga, calle por calle, barrio por barrio. De unos años para acá estos herederos de las estructuras paramilitares se han dedicado al expendio de drogas para el mercado local, a las prácticas extorsivas como los cobros por seguridad a toda actividad comercial e, incluso, al progresivo monopolio del comercio legal de bienes de consumo.

Desde el comienzo del siglo el norte del Valle del Cauca ha sido escenario de la disputa entre los grupos ilegales de Los Machos al mando de Diego León Montoya, 
alias Don Diego y Los Rastrojos del narcotraficante Wilber Varela, alias Jabón. Al parecer esa guerra fue ganada por Los Rastrojos, quienes pasaron a monopolizar el tráfico de drogas y procedieron a controlar extensas zonas rurales en el departamento del Valle del Cauca y zonas fronterizas con los otros departamentos que resultan estratégicas para el transporte de drogas y armas, y para la circulación de sus ejércitos. También extendió su dominio en los barrios de varios municipios del departamento, imponiendo su régimen de vigilancia y control.

Pero entonces aparece un nuevo enemigo en el horizonte representado por el clan Úsuga (los Urabeños) quienes, habiéndose enseñoreado en el norte del país desde la Guajira hasta Antioquia, pasando por la región del Magdalena, pretenden extender su poderío también aquí en la región. Se dice que vinieron de la mano del narcotraficante Víctor Patiño Fómeque, quien era un líder del cartel de Cali que se entregó a las autoridades colombianas en 1995 y fue extraditado a los Estados Unidos donde enfrentó cargos federales por narcotráfico. Cumplió una condena de seis años y negoció su libertad a cambio de información sobre rutas, negocios y nombres de sus antiguos socios. Quedó en libertad en el 2008 y pasó al sistema de protección de testigos de ese país. La delación de sus socios y la información sobre rutas que entregó a las autoridades americanas hizo que sus antiguos aliados se transformaran en sus enemigos y que exterminaran su familia y sus asociados más cercanos (reportes afirman que fueron 35 miembros de su familia y su círculo cercano). Esto último sería la motivación que le llevó a intentar recuperar su negocio y tomar venganza. De esta manera pasa a proponer la franquicia del departamento del Valle del Cauca al clan Úsuga e iniciar una guerra contra el clan de Los Rastrojos.

La respuesta de los Rastrojos ante esta invasión es aliarse con lo que quedaba de sus antiguos enemigos Los Machos, y crear una nueva organización a la que denominan La Empresa. La Empresa la fundan los hermanos Bustamante quienes -a propósito- solían trabajar para el mencionado Víctor Patiño Fómeque. Estas bandas, cuyo pie de fuerza está constituido en buena parte por antiguos paramilitares de las disueltas Autodefensas Unidas de Colombia (AUC), establecieron acuerdos de no agresión en 2011 que garantizaron una relativa paz, pero que se rompieron en 2013, sembrando el terror y la zozobra en varias zonas de la región y en particular en el municipio de Buenaventura. Lo que dice un informante sobre esta ruptura resulta especialmente llamativo por el lenguaje que usa. Dice que el pacto se rompió porque uno de los bandos quiso imponer un impuesto "ilegal" al embarque de cocaína en el puerto.

Esta rivalidad entre La Empresa y los Urabeños se extiende también a la ciudad de Cali donde las bandas se disputan el mercado interno de estupefacientes y el control de zonas urbanas donde quieren extender sus negocios. En el Distrito de Aguablanca se habla de la presencia del mencionado Clan Úsuga y La Empresa, además de Los Buenaventura y otro grupo denominado Los Caucanos. La presencia de estas bandas configura al menos dos campos de conflictos diferenciados: el de la rivalidad entre estos diferentes grupos por el control de las calles y la explotación del negocio del consumo de drogas; y el del monopolio de la violencia en los barrios en disputa con las pandillas o bandas preexistentes.

Estos nuevos campos de conflicto tienen reglas propias que alteran la dinámica tradicional de las pandillas. Las bandas se apoderan de los barrios para poner 
expendios de vicio y controlar el acceso y salida de personas, armas, dinero y alijos de droga. Estos grupos se proponen monopolizar el uso de la violencia en las calles y reprimen otras formas de violencia como las guerras de pandillas o la delincuencia común. Según dicen los informantes, es muy inconveniente que por cuenta de las pandillas o los delincuentes se les "caliente" la zona; es decir que por actos de violencia o por delitos que se cometan, se atraiga la atención de la fuerza pública y esto exponga la seguridad de los negocios de las bandas: "El otro día por Puertas del Sol se armó un tropel entre dos pandillas y persiguieron un man con armas y todo, y se iba a armar la plomacera ${ }^{8}$, hasta que salieron unos manes de una banda con fusiles y los amenazaron por calentar ${ }^{9}$ el barrio" (Informante 2, comunicación personal septiembre 2014). De esta manera se produce una paradójica pacificación donde ya casi no se dan las antiguas venganzas por honor de las pandillas y en cambio se han multiplicado las muertes por ajuste de cuentas. Muertes que ya obedecen a las reglas del negocio; se ha hecho un tránsito de los crímenes de sangre, con todo su contenido emocional y pasional, a la fría racionalidad de la muerte por encargo.

Las bandas forjan nuevos tipos de organización que crecen reclutando jóvenes que provienen de las pandillas (aunque no exclusivamente), y también se crean un conjunto de roles y oficios en torno a la circulación de la mercancía, con sus propias reglas y normas. Los jóvenes se emplean como vuelteros (que hacen encargos), es decir que participan en diferentes modalidades de la actividad relacionada con el negocio, como por ejemplo campaneros que son quienes vigilan las calles del barrio y dan aviso de la intrusión de extraños o de la fuerza pública; o como jíbaros o expendedores al por menor de la droga; llevando y trayendo armas o droga; o como sicarios para el ajuste de cuentas con los socios o empleados que no cumplen los acuerdos o en asesinatos selectivos a personas que de alguna manera estorban el negocio. Las nuevas reglas y normas prescinden de la solidaridad y la amistad pandillera y se concentran en la rentabilidad y la eficiencia de la operación y del negocio. La pandilla deja de ser un grupo donde se cuidan mutuamente y los miembros empiezan a atender sus propios intereses.

\section{El uso del territorio}

A pesar del derecho constitucional al libre tránsito por todos los territorios de la República hay que aclarar que las calles de los barrios marginales no pueden ser consideradas de ninguna manera espacio público, no se puede transitar en ellas con libertad porque estas calles tienen dueños, son propiedad de las pandillas y sus límites son las esquinas donde ha muerto un rival. Hay reglas inapelables sobre penetrar estos territorios, que castigan con la muerte cualquier intrusión y cualquier forastero tiene que entrar en compañía de un lugareño para no exponerse a innumerables peligros.

Antaño las pandillas solían tener un fuerte vínculo identitario con su territorio dado que este siempre fue un importante elemento de su trayectoria vital: la calle estaba asociada a un amplio conjunto de representaciones sobre la

8 Plomacera hace referencia a un abaleo.

9 Calentar en este contexto significa un incremento de la violencia. 
amistad y la camaradería, el goce, la rumba, el peligro, la muerte, el alcohol y la droga. La calle era el escenario de los acontecimientos: cada anécdota de la mitología personal de los pandilleros corresponde a una localización específica. Ese pequeño territorio -a veces unas pocas calles que limitan con las fronteras invisibles del odio- está sujeto a un conjunto de reglas simbólicas que remiten a un sistema cultural del honor (Peristiany, 1968; Pitt-Rivers, 1968; Ignatieff, 1999; Cerbino, 2006). Este código honorífico prescribe la defensa del territorio como una obligación moral y manda que cualquier miembro de otra pandilla que ose violar el perímetro, debe ser perseguido y muerto.

Las escaramuzas entre pandillas siempre ocurrían en torno a las fronteras y en esta situación, el combate era la condición privilegiada para reactualizar la solidaridad del grupo, para exhibir la valentía y la audacia, y para probar quien es más hombre. La defensa del territorio y la obligación moral de la venganza eran los puntos más altos del honor, y uno de los aspectos más importantes de la justificación ideológica de la violencia entre pandillas. Los mojones de esas fronteras eran los muertos o los actos de violencia que configuran esas geografías del odio.

El espacio para las pandillas solía ser el territorio del afecto y de la identidad, del recuerdo y de la historia, de la pertenencia y el arraigo. Las fronteras territoriales eran los espacios de redefinición del honor, eran frentes de guerra, el lugar para las pruebas de valentía, el límite de la diferencia, los bordes que separan el amor del odio. El territorio era el tamaño del mundo.

Con la progresiva influencia de las bandas criminales hoy el espacio en los barrios de las pandillas deja de ser lo que era y se transforma en un territorio de la estrategia, en un lugar de tránsito interconectado geográficamente por el cual circulan armas, dinero y droga, o como dicen en el barrio: los fierros, el billete y la merca. Ya no más el bucólico territorio del parche (sitio de reunión y por extensión denominación del grupo) y los recuerdos de adolescencia, sino las vías del tráfico y el negocio. Este nuevo uso del territorio crea una nueva conflictividad por el control monopólico del mercado local de las drogas -el microtráfico o narcomenudeo del que hablan los medios-, el ejercicio de prácticas delictivas bajo la forma de cobros extorsivos en el territorio, y el dominio de las calles como rutas seguras para el tránsito de las mercancías y el desplazamiento de personas. La población -en ese territorio que se transforma- es un mercado cautivo para la venta y consumo de droga, y por esta razón fueron eliminados (con amenazas y muertes) en Marroquín y en otros barrios aledaños, los jíbaros o expendedores independientes de marihuana y otros psicoactivos: "A todos esos pelaos les dieron ${ }^{10}$; aparecieron muertos como seis" (Informante 3, comunicación personal 11 de noviembre de 2014). Ellos fueron reemplazados por empleados de las bandas que atienden sitios de venta de drogas que se denominan ollas, bajo el control de las bandas. Estas bandas imponen a los consumidores comprar solo en sus sitios y les prohíben comprar en la competencia y siempre habrá ocasiones de reiterar esta amenaza con alguna víctima propiciatoria.

En cuanto a la manera en que las pandillas ocupaban su territorio también se han producido cambios significativos por el efecto intimidatorio y controlador de las bandas. Los pandilleros han abandonado las esquinas muy visibles o 
las áreas abiertas como la cancha de fútbol y se ubican a mitad de las cuadras, más cerca de sus casas: "Uno ya los ve con miedo, ya se han ido quitando de las esquinas, están más aplacados" (Informante 3, comunicación personal 11 de noviembre de 2014). Como dicen ellos, es menos boleta, es decir que llaman menos la atención. También ocurre que los miembros de las pandillas que empiezan a trabajar con las bandas se deslocalizan del parche pandillero y pasan a una condición ubicua por medio del uso de los teléfonos celulares: el celular pasa a ser su oficina. Son ubicables para sus patrones en cualquier momento, independendientemente del sitio donde se encuentren.

La presencia de las bandas incluso ha reorganizado las famosas fronteras invisibles, las demarcaciones tradicionales del territorio de las pandillas no operan para ellas, pueden por ejemplo hacer presencia en cualquier barrio con un grupo de jóvenes reclutados en otro territorio sin que las pandillas protesten: "Allí alquilaron una casa y se la pasan afuera y mostrando las armas, nadie se mete con ellos" (Informante 2, comunicación personal 24 de enero de 2014). Las bandas alquilan una casa, ponen en ella a ocho o diez de sus miembros respaldados con pistolas y fusiles, y el campo de conflicto se reconfigura al menos de dos maneras: una nueva conflictividad con las pandillas locales en un proceso más o menos tenso de cooptación o coexistencia, y en el caso de que una banda rival pretenda disputar el territorio o una pandilla se rebele contra la dominación, habría una confrontación armada resuelta fundamentalmente con el asesinato selectivo de los líderes de las agrupaciones. Ya el territorio no está gobernado por un código de honor pandillero sino por las reglas de la delincuencia organizada, cuyos propósitos difieren sustancialmente. Este fue el caso de la pandilla de la Calle Sahumerio en Marroquín, que fue cooptada por la delincuencia organizada pero que luego decidió resistirse a esa dominación. Fue vencida con varios asesinatos colectivos.

Las escuelas en estos barrios también han sido afectadas, la delincuencia empieza a crear conflictos nuevos que desbordan su función y sus capacidades. Los muros de las instituciones escolares siempre han servido de límite real y simbólico a las dinámicas relacionales de la calle y el barrio; en su interior impera otro orden y disciplina, un uso y control del tiempo y se trata de un espacio completamente diferente del que se da en las esquinas habitadas por pandilleros. En general, en las escuelas los jóvenes indisciplinados y violentos, o los jóvenes que pretenden delinquir, son de alguna manera controlados o expulsados. Pero cuando estos jóvenes, ya de por si retadores y desobedientes de la norma, se vinculan con el tráfico de drogas, cambian estratégicamente su comportamiento y aprenden a guardar un bajo perfil para poder expender vicio dentro del colegio. La conflictividad del barrio penetra de esta manera al interior de la escuela, sus fronteras se vuelven porosas y los problemas de la calle empiezan a alterar el orden y la disciplina en el interior de la institución. Comienza así una difícil situación de control y negociación con este tipo de problemas.

\section{El uso del tiempo}

El tiempo de la vida pandillera también se transforma. Perea (2007) habla del tiempo de la pandilla como un tiempo paralelo: un tiempo del "desparche", 
del ocio, por fuera de la disciplina escolar, por fuera del tiempo laborioso del empleo; y que contrasta con los otros segmentos sociales mejor adaptados a la productividad social, que tienen rutinas y horarios, horas de colegio y oficina. Los pandilleros no tienen esas obligaciones, o no las tenían, se levantan hacia el mediodía, al final de la tarde empiezan a reunirse en las esquinas donde conversan y departen, juegan fútbol y se drogan, matando el tiempo; y ya entrada la noche pueden hacer rondas de pequeños atracos y recorridos por el barrio y consumir licor y más droga. Con el ingreso en las bandas y en la rutina de sus actividades, el uso del tiempo es una cosa completamente distinta: se pasa al tiempo de la disponibilidad, del compromiso, de la obligación. Con un celular en la mano estos muchachos tienen que estar disponibles para vueltas de droga, dinero, armas y muerte. Se trata ya de un tiempo disciplinado y regulado por las necesidades del negocio, que rompe con el ocio de la pandilla. No es un tiempo de amistad y de departir con sus pares sino de oficio y de servicio, de ocupación y de seguir órdenes.

De ese tiempo de ocio y de desborde, de goce, de exceso y de violencia, se pasa a un tiempo productivo y laborioso en la industria del crimen. De un tiempo pandillero que sabe que su vida será corta, que sabe que al final hay una muerte violenta esperándolo, de ese tiempo que tiene el signo trágico del destino y la brevedad, un tiempo pandillero que tiene la frontera de la muerte tan cercana y tan visible, un tiempo que avanza raudo hacia la fatalidad, se pasa de pronto a un tiempo rentable, a un tiempo utilitario y al servicio de otras cosas, un tiempo con movimientos estratégicos hacia el futuro. Al pandillero le compran el know how de la violencia, su experticia y su falta de compasión, su actitud transgresora y agresiva; pero esa violencia que cumplía un papel de expresión del resentimiento y de ritual de identidad y solidaridad grupal pasa a ser un valor agregado y ahora se dirige a los objetivos del negocio, es una suerte de sector servicios del narcotráfico; ese tiempo de violencia se compra, se vuelve mercancía, adquiere un valor; la muerte o la vuelta valen el tiempo socialmente necesario para producirlas" , y su precio está sujeto a las leyes de oferta y demanda del mercado. Ingresan en la forma mercancía donde el tiempo es oro y la velocidad de circulación incrementa las utilidades.

Este tiempo productivo busca ser eficiente y rentable y no es extraño que empiece a usar técnicas y teorías de la administración moderna, y no resulta gratuito que una banda criminal reciba el nombre de La Empresa, y que la organización de los servicios criminales reciba el nombre de oficina. Tienen sueldo y primas de servicio, un informante afirma que en La Empresa le pagan un millón de pesos mensuales y que tienen primas millonarias que hacen que puedan reunir hasta veinte millones de pesos en un mes. Con esto, el ocio y el tiempo se dedican al gasto ostensible de la rumba y las amantes: "Yo tenía un básico de un millón doscientos, cuando no hay nada que hacer me gano eso. Pero cuando me mandan a hacer alguna vuelta todo eso lo pagan". "Depende de la vuelta, a veces no es sino ir a hablar con un señor en una oficina y preguntarle por qué se atrasó con un pago. Uno va decentemente y él le contesta a uno y llegan a un acuerdo, normal;. Ya si a uno le toca volver ya no es tan amable la cosa". "Dependiendo

ll Siguiendo por supuesto las tesis de la economía política clásica de Smith y Marx sobre el valor. 
de las vueltas uno se puede poner hasta 20 millones de pesos en un mes" (Informante 1, comunicación personal, 12 de agosto de 2014).

El tiempo invertido en la "vuelta", en el asesinato, implica una apropiación simbólica y racional de la temporalidad. Ahora el tiempo es valioso, es dinero, está regulado, medido, secuenciado. Es un tiempo útil, que genera utilidades, que crea riqueza, es un tiempo enajenado in extremis, tiempo de destrucción y muerte bajo la égida de la forma mercancía. Una racionalidad completamente ajena a las necesidades vitales, donde el significado, el propósito y la inteligencia del acto son ajenos a la persona que lo realiza. Una forma de alienación laboral acentuada, donde a la pérdida del sentido del trabajo se suma el daño social que produce (Marx, 1997).

\section{Las motivaciones de la violencia}

Las motivaciones de la violencia cambian: si antes teníamos guerras de pandillas por la venganza de sus compañeros caídos en combate, hoy -cooptadas por las bandas criminales- prima la modalidad de "ajuste de cuentas" (Camacho \& Guzmán, 1990). Venganza y "ajuste de cuentas" significan dos cosas totalmente distintas: la venganza en las pandillas es su más alto punto de honor.

Dado que como hemos dicho las pandillas son una comunidad emocional, de fuertes lazos afectivos, la muerte de un compañero es vivida con gran dolor y es una afrenta que se repara solo con la muerte. La identidad del grupo, sus sentimientos de orgullo y dignidad están fincados en la solidaridad; para ellos la venganza es un "crimen de sangre" que hay que cobrarlo a la otra pandilla con una víctima, que no necesariamente tiene que ser quien ha matado a su compañero, basta que sea miembro del grupo contrario. Esto implica una forma de violencia ritualizada (Spieremburg, 1998) cuya motivación se vincula con la identidad y los lazos de afecto del grupo. La violencia pandillera se caracterizaba por el resentimiento, el odio al enemigo y el deseo de venganza. Se trata de una violencia llena de emociones y de afecto; los deseos de venganza serán tan grandes como el dolor por la pérdida de un amigo o tan grandes como el orgullo y la dignidad ofendidos. Hoy esa violencia se ve obligada a refrenarse y a ponerse en el régimen de la productividad. Si antes la rabia y el resentimiento eran canalizados hacia el odio por el enemigo, en la banda deben controlarlo aún más y lograr un mayor control emocional, se pasa de un estado de emociones y sentimientos intensos a uno de frialdad e indiferencia.

Por su parte el "ajuste de cuentas" obedece a una razón completamente diferente: no se trata de lavar el honor mancillado del grupo, no es un crimen movido por la pasión o las emociones que derivan de la muerte de un ser querido. Su motivación radica en faltas cometidas por la víctima en las actividades relacionadas con los negocios ilegales, se castiga el incumplimiento de un contrato o la violación de alguna regla. No tiene connotaciones afectivas y por el contrario exige un distanciamiento emocional y una racionalidad utilitaria. En la medida en que se produce una transformación del honor pandillero y sus aspectos rituales a una racionalización de la violencia y una finalidad práctica, los valores de la pandilla se trastocan. En realidad, pasan a ser otra cosa: la violencia se vuelve negocio y de esta manera se naturaliza: "No, normal, si no lo hace uno lo hace cualquier otro" (Informante 1, comunicación personal, 12 de agosto de 2014). Supone 
el informante que cualquier persona puesta en esas circunstancias optaría por el delito, con independencia de su criterio moral o sus principios.

Se puede proponer un modelo acerca de las características y transformaciones de la violencia (Spieremburg, 1998), imaginándonos una línea continua que va de un polo de emocionalidad a otro polo de racionalidad, y de un polo de formas rituales a otro de formas de instrumentación. Esta es una buena forma de describir lo que ocurre con la transformación de la violencia pandillera. Este modelo propone que hay un conjunto de violencias que pueden describirse como cargadas emocionalmente, unas violencias que expresan pasiones y emociones intensas, como en el caso de los crímenes pasionales o la violencia pandillera; y otra polaridad de la violencia en la cual hay un alto control emocional, donde se mata con frialdad como en el caso del sicariato. En el otro eje se pueden observar formas de la violencia que son ritos relacionados con la identidad grupal, como las iniciaciones en las maras o pandillas; y en el otro extremo una violencia desprovista de simbolizaciones y significados identitarios, que se vuelve un instrumento para el negocio de la delincuencia.

En un principio la violencia homicida en los pandilleros está llena de resentimiento y de odio, se mata con rabia, la muerte era un acto pasional, una exacerbación de la ira y la destructividad. El entrenamiento "para endurecer el corazón" que siguen los pandilleros consiste en poder focalizar la rabia que nace del resentimiento y la estigmatización, que nace del ataque a los suyos y a sí mismo, y poder desfogarla sobre el enemigo, no "meterle mente", no oponer ninguna consideración moral o sentimiento de culpa. Una vez han "endurecido" el corazón su progresivo ingreso en el mundo de la delincuencia organizada les impone ahora, controlar esa rabia, no experimentar ni siquiera emociones negativas hacia sus víctimas. Ahora la culpa está aún más domeñada, se mata sin compasión, sin emoción, es un acto racional, frío, calculado. Ahora está al servicio de la forma mercancía: Yo no tengo nada que ver, alguna cosa mala habrá hecho" (Informante 1, comunicación personal 24 de agosto de 2014).

\section{La subjetividad cambiante}

Estos cambios en los valores y las prácticas, esta racionalización e instrumentación de la violencia producen a su vez un modelamiento particular de la subjetividad del pandillero. Modifica su configuración emocional, cambia la manera de regular sus emociones: el pandillero experimenta emociones intensas y apasionadas y estas se exteriorizan con facilidad e inmediatez. Esta configuración emotiva es adaptativa y funcional a un mundo violento donde la supervivencia depende de estas rápidas y espontáneas reacciones agresivas, donde el respeto y el estatus se consiguen por violentar a otros en eventos agonísticos y rituales donde se prueba la masculinidad. En la banda de la delincuencia organizada, la hombría deja de ser una exhibición de violencia y hostilidad, irreflexiva y desordenada, y se le impone un nivel de mayor autocontrol y escisión emocional. La violencia tiene que controlarse y usarse de manera selectiva y como una decisión estratégica. Esta violencia de la banda se desliga del honor pandillero, se desliga del vínculo emocional con el grupo y se racionaliza en una ética utilitaria; ella sirve a otro propósito, debe ser rentable. 
La pandilla es un grupo de pares donde las relaciones entre sus miembros tienden a ser más horizontales y menores los diferenciales de poder, si lo comparamos con una estructura como las bandas criminales. Su organización social es más espontánea y sus propósitos no son los de la producción económica; ellos se reúnen para protegerse, para apoyarse, para establecer vínculos emocionales e identitarios. En cuanto a su configuración emocional hay que recordar que los pandilleros experimentan culpa y remordimiento cuando cometen su primer homicidio, lo cual es señal de que en su socialización previa han logrado interiorizarse estas formas autorrestrictivas de la moral y la psique, estas estructuras superyoicas, si usamos el lenguaje freudiano (Freud, 1981).

Pero el ingreso en la pandilla y todo el proceso de socialización secundaria que ocurre a nivel de pares y habitando las esquinas, se dirige a eliminar la compasión, a no sentir culpa y remordimiento por el daño infligido a otros, y a controlar las emociones de lástima y el miedo, para ser alguien más capaz de ejercer violencia, alguien menos compasivo. Se realiza un progresivo aislamiento emocional encaminado a desvincular los sentimientos morales de la comisión de actos violentos. Entrando a aspectos propiamente psicológicos, la vida en la delincuencia exige un complejo proceso de domesticación de la culpa, se pasa de un sentimiento inicial de remordimiento frente al primer muerto a una progresiva disminución de su valor y de la intensidad de este sentimiento con las otras víctimas, al punto de que ese sentimiento puede llegar a ser ahogado completamente y suprimido de la conciencia.

En la banda criminal este aislamiento emocional y esta desvinculación de los sentimientos morales, que hace posible el ejercicio del delito, se exacerba, y los niveles de control de la culpa y de las emociones se incrementan al punto que, de cambios cuantitativos se pasa a cambios cualitativos. Se pasa a otra estructuración de las emociones: todavía más escindidas, más controladas y sirviendo a otra lógica de canalización de la violencia. La moral es reemplazada por un comportamiento estratégico definido por las reglas del juego de la delincuencia.

Cuando se inquiere a un delincuente sobre su responsabilidad en un homicidio durante un robo, este responde: "son cosas que pasan" (informante 1 , comunicación personal 24 de agosto de 2014), como si fueran simplemente las reglas de un juego donde alguien gana y alguien pierde, y aún queda el recurso del sistema cultural de la masculinidad y el delincuente afirma: "un hombre no se arrepiente nunca de lo que hace" (informante 1, comunicación personal 24 de agosto de 2014), Con lo cual se muestra una externalización, una proyección al exterior, de esas determinaciones y no una motivación personal. No es algo que se asume como una consecuencia de la propia acción, no es algo que se vincula con la intencionalidad, es simplemente una consecuencia no deseada, o por lo menos no prevista de una acción en la que no importa la vida de las personas. En este caso las determinaciones habría que buscarlas más en factores situacionales que en factores motivacionales (Zimbardo, 2008); en la medida en que se produce una suerte de anulación del yo y la conducta está determinada por la adaptación pragmática a una situación. La conducta es movida acorde con las necesidades de una situación y no por motivaciones de carácter moral.

La estructura de la banda, al contrario de la pandilla, es muy vertical. El poder está claramente jerarquizado, con líneas de mando definidas y órdenes precisas, 
y esta distribución del poder hace que los sujetos que obedecen tengan un conocimiento muy parcial de la inteligencia del proceso, desconocen muchas veces las razones por las cuales se toman las decisiones y parte de su trabajo es, precisamente, no preguntar. De esta manera el trabajo en el crimen organizado resulta ser la máxima expresión de la alienación, todo en él está compartimentalizado, separado, desconectado: no solo hay desconexión entre los actos criminales y los sentimientos de culpa, remordimiento o compasión que pudieran suscitar, sino que también tienen fragmentaciones cognitivas. Al ser miembros de una cadena productiva -una banda criminal-, se desentienden de los otros aspectos del negocio, su responsabilidad en los actos se disminuye cuando no se anula por completo. Hay un aislamiento emocional y cognitivo casi total. Estas estructuras organizativas verticales de las bandas criminales generan la más radical segmentación de los procesos y una desconexión cognitiva y afectiva de la conducta.

En este tipo de estructuras verticales, como las empresas criminales, resultan tan determinantes las reglas del juego en cada escenario, que los actores mudan su comportamiento de manera automática cuando van de un contexto a otro: como miembros de bandas rivales son enemigos en las calles, pero en la cárcel se relacionan bien, conversan, se hacen amigos e incluso juegan al fútbol o al parqués. Y lo hacen a sabiendas de que una vez queden en libertad tendrán que matarse. Las lógicas de los espacios y las instituciones cambian radicalmente, e imponen un comportamiento estratégico donde priman los aspectos situacionales sobre los motivacionales, como diría Zimbardo (2008). Estos acomodamientos a las circunstancias exigen el modelamiento psíquico que mencionamos más arriba.

\section{Conclusiones}

Los testimonios sobre la violencia urbana recogidos con las pandillas y los líderes comunitarios en el sector del jarillón del río Cauca en Alfonso López y en el barrio Marroquín II en el distrito de Aguablanca muestran una transformación de la conflictividad violenta de los grupos de jóvenes, que cada vez depende menos de las funciones rituales de afirmación identitaria y resistencia a la marginación. Al parecer la violencia en estas calles está cada vez más movida por la racionalidad utilitaria de las economías ilegales, y esto ocurre por la progresiva penetración de la delincuencia organizada en los barrios con el propósito de controlar y monopolizar el tráfico y expendio de drogas.

Cuando los jóvenes de las pandillas se van involucrando con las bandas criminales la violencia se vuelve un instrumento para obtener ganancias y beneficios en torno a un negocio muy lucrativo. De esta manera, los actores de violencia van mudando sus motivaciones, su manera de usar el tiempo, su manera de habitar el territorio, e incluso el control de las emociones. Las motivaciones o justificaciones de la acción violenta se apartan del resentimiento por la condición marginal y la construcción de la masculinidad; y pasan a ser la ganancia económica y las reglas del negocio. El uso del tiempo pasa del tiempo paralelo, ocioso y marginal de las pandillas al tiempo productivo y diligente del trabajo ilegal. El territorio pasa de referente identitario a corredor estratégico. La subjetividad del 
joven violento se vuelve más reflexiva y autocontrolada, porque en el mundo del crimen organizado es mejor no matar con rabia; se pasa del odio al enemigo a la fría racionalidad de la transacción comercial.

Los cambios en la subjetividad del joven pandillero, su configuración emocional parece modelada por la preeminencia de un mecanismo psicológico inconsciente que se llama aislamiento emocional. Mediante este mecanismo de defensa las acciones se desligan de los sentimientos y emociones que deberían acompañarle, y de esta manera se extinguen la compasión y el sentimiento de culpa.

Una recomendación para procesos de intervención con jóvenes delincuentes es orientar el trabajo psicológico a una emergencia de la culpa, la empatía y la compasión en estos sujetos. El problema ahora se hace más complejo porque el ingreso en bandas criminales implica para los sujetos una exacerbación de los mecanismos de aislamiento emocional, además de generarles pingües ganancias económicas.

\section{Referencias}

Alcaldía de Santiago de Cali. (2015). Cali cómo vamos. Recuperado de www.calicomovamos.org.co

Bettelheim, B. (1998). Educación y vida moderna. Bogotá, Colombia: Grijalbo.

Camacho, A. y Guzmán, A. (1990). La violencia urbana en Colombia: Síntesis de un Estudio exploratorio en una ciudad colombiana. Boletín Socioeconómico, (20), 42-56.

Cerbino, M. (2006). Jóvenes en la calle. Barcelona, España: Anthropos.

Cruz-Sierra, S. (2014). Violencia y jóvenes: pandilla e identidad masculina en Ciudad Juárez. Revista Mexicana de sociología, 76(4), 1-14.

Dillow, G. (2013). El capo del cartel de Cali, Víctor Patiño Fómeque, reanuda el tráfico de drogas en Colombia. Dialogo-Américas. Recuperado de https://dialogo-americas.com

Elías, N. (1990). El proceso civilizatorio. Bogotá, Colombia: Fondo de Cultura Económica.

Freud, S. (1981). Inhibición, síntoma y angustia. Madrid, España: Biblioteca Nueva.

Galtung, J. (2003). Tras la violencia tres $R$ : reconstrucción, reconciliación, resolución. Afrontando los efectos visibles e invisibles de la guerra y la violencia. Guernica-Luno, España: Bakeaz/Gernika Gogoratuz.

Hernández, T. (2015). Masculine Protest and Gender Performance Among Mexico City's Young Offenders. Masculinities a journal of identity and culture, (4), 47-69.

Ignatieff, M. (1999). El honor del guerrero. Madrid, España: Taurus.

Marx, K. (1997). Manuscritos económico filosóficos de 1844. México D. F., México: Fondo de Cultura Económica.

Ordóñez, J. (2015). Honor y magia en la vida pandillera (tesis de doctorado). Universidad del Valle, Cali, Colombia.

Perea, C. M. (2007). Con el diablo adentro. México D. F., México: Siglo XXI.

Peristiany, J. G. (1968). El concepto de honor en la sociedad Mediterránea. Barcelona, España: Labor.

Pitt-Rivers, J. (1968). Honor y categoría social. En J. G. Peristiany (Ed.), El concepto de honor en la sociedad mediterránea (pp. 21-76). Barcelona, España: Labor. 
Ramírez, Elkin. (2007). Órdenes de hierro. Bogotá, Colombia: La Carreta.

Rubio, M. (2007). Pandillas, rumba y actividad sexual. Bogotá, Colombia: Universidad Externado de Colombia.

Spieremburg, P. (1998). Violencia, castigo, el cuerpo y el honor: una revaluación. En V. Weiler (Ed.), Figuraciones en proceso (pp. 116-151). Bogotá, Colombia: Universidad Nacional de Colombia.

Valenzuela, J. M., Nateras, A. y Reguillo, R. (2007). Las Maras. Identidades juveniles al límite. México D.F., México: Universidad Autónoma de México.

Vigil, D. (1988). Barrio gangs: Street life and identity in Southern California. Austin, US: University of Texas.

Zimbardo, P. (2008). El efecto Lucifer. El porqué de la maldad. Barcelona, España: Paidós. 
